\title{
A sensitive electrochemical sensor for Moxifloxacin Hydrochloride based on Nafion/graphene oxide/zeolite modified carbon paste electrode
}

\author{
Amany M. Fekry ${ }^{a, c *}$, Soha A. Abdel-Gawad ${ }^{a}$, Shereen M. Azab ${ }^{b}$, Alain Walcarius ${ }^{c}$ \\ ${ }^{a}$ Chemistry Department, Faculty of Science, Cairo University, Giza-12613, Egypt. \\ ${ }^{b}$ Pharmaceutical Chemistry Dept., National Organization for Drug Control and Research [NODCAR], 6 Abu Hazem \\ Street, Pyramids Ave, 29, Giza, Egypt. \\ ${ }^{c}$ Laboratoire de Chimie Physique et Microbiologie pour les Matériaux et l'Environnement (LCPME), UMR 7564 \\ CNRS - Université de Lorraine, 405 rue de Vandoeuvre, 54600 Villers-les-Nancy, France
}

\begin{abstract}
A carbon paste electrode (CPE) modified with Nafion, Graphene oxide and zeolite has been prepared and characterized, and the resulting Nafion/Graphene oxide/Zeolite modified carbon paste electrode (N/G/Z/MCPE) has been applied to the electrochemical detection of Moxifloxacin hydrochloride (MOXI). It exhibited a good electrocatalytic activity in phosphate buffer (optimum at $\mathrm{pH}$ 7.4), as pointed out by cyclic voltammetry (CV), and N/G/Z/MCPE can be exploited for MOXI detection by chronoamperometry, electrochemical impedance spectroscopy and differential pulse voltammetry. This latter was the most sensitive one and gave rise to a linear calibration curve in the 0.04 to $250 \mu \mathrm{M}$ concentration range, with limits of detection and qualification estimated at $1.0 \mathrm{nM}$ and $3.3 \mathrm{nM}$, respectively. Contrary to previous electrochemical sensors for MOXI (e.g., CPE modified with metal nanoparticles), this new sensor can be used for multiple successive analyses without needing to refresh its surface.
\end{abstract}

Keywords: Moxifloxacin Hydrochloride; Carbon Paste Electrode; Nafion; Graphene Oxide; Zeolite.

*corresponding author E-mail: amanym.fekry@gmail.com 


\section{Introduction}

MOXI (1-cyclopropyl-6-fluoro-1,4-dihydro-8-methoxy-7-[(4aS,7aS)-octahydro-6Hpyrrolo[3,4-b]pyridin-6-yl]4-oxo-3-quinoline carboxylic acid), also called moxifloxacin hydrochloride (see scheme 1) is an antibiotic used to heal some respiratory skin and soft tissue infections without complications [1]. MOXI is one of the fourth-generation fluoroquinolones antibiotics with minor toxicity. Fluoroquinolones are antibiotics working actively against bacteria, both gram-positive and gram-negative types [2]. World Health Organization recommends the usage of MOXI in medicine [3,4]. Several sophisticated methods have been reported in the literature for MOXI detection, such as high performance liquid chromatography [5-7], capillary electrophoresis [8] or spectrophotometry [9-11]. However, these approaches are often timeconsuming and require rather expensive instruments [12]. It is thus necessary to develop new and simple sensors for MOXI.

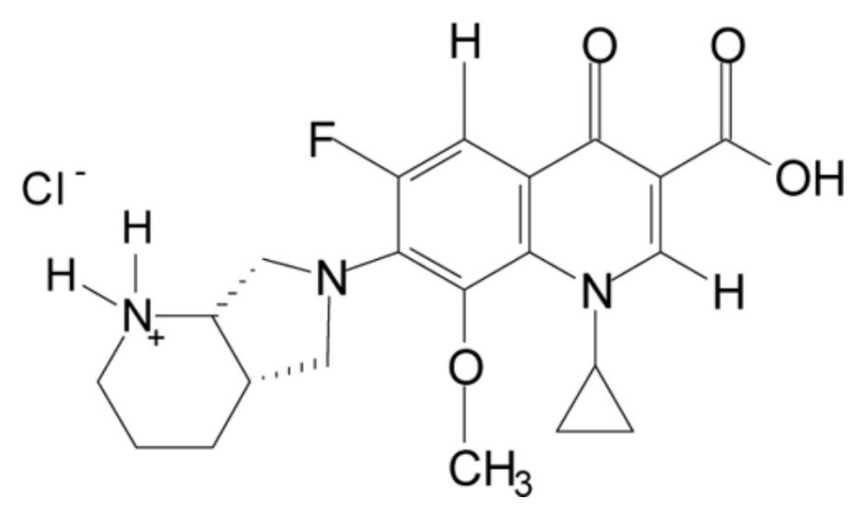

Scheme 1. Chemical structure of MOXI.

Electrochemical sensors are powerful tools due to their portability, somewhat simple use and wide applicability [12-14]. Dealing with MOXI determination, potentiometric sensors have been proposed $[15,16]$, but they suffered from low sensitivity and long response time, among other limitations. This has required the development of other electrochemical sensors involving notably 
the preconcentration of the analyte and its subsequent detection by amperometry [17]. CPE is appropriate for the determination of various substances owing to their attractive electrochemical features, easy surface renewability, low cost, and convenient modification with a wide range of materials and reagents [18]. Chemically modified carbon paste electrodes have been widely implemented in order to bring suitable features to the electrode surface, which are likely to improve the sensitivity and selectivity and to lower detection limits, thanks to the particular properties of well selected modifiers [19-25]. In a previous work [26], we proposed the use of CPE modified with silver nanoparticles as a simple and sensitive sensor for MOXI. Yet operating quite well as single-use electrode, this sensor suffered from poisoning upon successive analyses, probably due to adsorption of the oxidized products of MOXI onto the silver surface, suppressing therefore its electrocatalytic response. To circumvent this drawback, it is thus necessary to look for new advanced modifiers compatible with repeatable successive analyses of MOXI with a low-cost, simple and sensitive sensor. This is what we propose here, by exploiting the synergistic properties of three additives to the CPE, i.e. GO, zeolite and Nafion.

Graphene oxide (GO) has been largely used by electrochemists due to its outstanding properties, numerous ways of chemical functionalization, high thermal and electrical conduction, transparency and good mechanical properties $[27,28]$. GO offers attractive electrocatalytic features that can be exploited in electrochemical sensing [29,30], as well as high specific surface areas that enhances the loading of catalysts and/or analytes [31-33], both being attractive for effective MOXI accumulation via $\pi-\pi$ interactions (between GO and the aromatic part of drug) and subsequent electrocatalytic detection. Zeolites are microporous three-dimensional crystalline aluminosilicate materials with high surface area, adsorptive capacity and ion-exchange properties, which have been exploited in various applications [34], including electrochemical sensing and biosensing 
$[35,36]$. Zeolite modified electrodes were used in preconcentration electroanalysis, electrocatalysis, indirect amperometric detection and biosensors [37-41]. In particular, Al-rich zeolites (as that used here) are likely to increase the hydrophilic character of modified CPE [38], which could be useful here to increase the electrode surface area exposed to the MOXI analyte. Nafion has been used for a long time as solid polymer electrolyte or membranes in fuel cells [42] thanks to its unique thermal, mechanical and chemical stability. It also found applications in the field of electrochemical sensors due to its highly conductive to cations $[43,44]$ and can be combined to other materials in order to improve the physical and/or chemical properties, opening the door to new applications [45]. It can be used as a binder due to its good stability, while keeping permeability to cations (such as MOXI), and is expected to act as a protective layer against surface fouling, which might be attractive for multiple successive measurements.

In this work, we have developed a Nafion/Graphene oxide/Zeolite modified CPE for MOXI determination, by exploiting the additive properties of these three modifiers. After investigation of the electrochemical response of N/G/Z/MCPE using various techniques, this novel simple sensor was optimized for the fast, sensitive and robust determination of MOXI, offering the possibility of successive determinations with the same electrode, contrary to CPE modified with metal nanoparticles [26], for instance. The utility of the sensor is demonstrated for real sample analysis (urine containing MOXI and paracetamol) by differential pulse voltammetry.

\section{Experimental}

\subsection{Materials and reagents}

The chemicals utilized in this work were MOXI (from Sabaa International Company for Pharmaceutical and Chemical Industries SAE, SABAA), and graphite powder, Nafion solution, 
GO and Y-type zeolite (all from Sigma Aldrich). Phosphate buffer solution (PBS, pH 5.8-7.4) was used as the supporting electrolyte for MOXI detection; $\mathrm{pH}$ values were adjusted using $0.1 \mathrm{M} \mathrm{NaOH}$ and/or $0.1 \mathrm{M} \mathrm{HCl}$ using Jenway 3510 Standard Digital pH meter. All solutions were prepared utilizing Triple distilled water. All measurements were performed at room temperature.

\subsection{Sensor (N/G/Z/MCPE) preparation}

Several carbon paste electrodes have been prepared. Bare CPE was obtained by blending $0.50 \mathrm{~g}$ graphite powder with drops of paraffin oil $(0.3 \mathrm{ml}=0.24 \mathrm{~g})$ using a glassy mortar for $30 \mathrm{~min}$ [46]. To construct Nafion modified carbon paste electrode (N/CPE), a mixture of Nafion solution, paraffin oil and graphite powder $(10: 15: 75, \mathrm{w} / \mathrm{w}, \%)$ giving $1 \mathrm{~g}$ mixture moved to the glassy mortar and homogenized by adding $2.0 \mathrm{ml}$ of dichloromethane that was evaporated at room temperature [47] forming N/CPE. Then, series of CPEs modified with Nafion, GO and/or zeolite particles (N/G/Z/MCPE) have been prepared from the following paste compositions (expressed in w/w \%): Nafion (10), paraffin oil (15), GO (0, 5, 10, 15, 20 or 25), zeolite $(25,20,15,10,5$ or 0$)$. After mixing the solid modifiers particles $(\mathrm{N}, \mathrm{G}$ and $\mathrm{Z}$ ) in a mortar for $30 \mathrm{~min}, 2.0 \mathrm{ml}$ of dichloromethane was added, followed by magnetic stirring for $24 \mathrm{~h}$ to form a homogenous dispersion of GO and/or Zeolites in Nafion matrix. This mixture was then added to the graphite powder and homogenized with the paraffin oil binder. The paste was filled into a teflon tube with stainless steel contact and pressing it well on filter paper to obtain a smooth uniform surface.

\subsection{Apparatus}

Cyclic voltammetry (CV), differential pulse voltammetry (DPV), chronoamperometry (CA) and electrochemical impedance spectroscopy (EIS) measurements were performed using an EC-Lab SP 150 Potentiostat electrochemical workstation (BioLogic, France). EIS data were recorded at $10 \mathrm{mV}$ ac amplitude in the frequency range of $1.0 \mathrm{mHz}$ to $100 \mathrm{kHz}$. EC-Lab software is utilized 
for modelling. A typical three-electrode cell of $25 \mathrm{ml}$ volume comprising a platinum rod as a counter electrode (CE), a saturated calomel electrode (SCE) as reference electrode (RE) and $\mathrm{N} / \mathrm{G} / \mathrm{Z} / \mathrm{MCPE}$ as the working electrode (WE), was utilized. A digital pH-meter (Hanna instruments, Italy) was used for $\mathrm{pH}$ adjustments in the electrochemical cell.

Scanning electron microscopy (SEM) measurements were performed with the aid of a SEM Model Quanta 250 FEG (Field Emission Gun) associated with EDX Unit (Energy Dispersive X-ray Analyses, FEI company, The Netherlands).

\subsection{Analysis of biological samples}

Urine aliquots were collected from healthy volunteer. A volume of $1.0 \mathrm{~mL}$ was diluted with 400 $\mathrm{mL}$ of PBS (pH 7.4) and then centrifuged for $5 \mathrm{~min}$ at $5000 \mathrm{rpm} .0 .7 \mathrm{~mL}$ acetonitrile was added as precipitating agent to get rid of protein residues, and the supernatant was kept for analysis. All tests were treated according to the ethical guidelines for biomedical research involving human subjects, which was approved by the Egyptian Network of Research Ethics Committees.

\section{RESULTS AND DISCUSSION}

\subsection{Fabrication and characterization of the modified electrode}

The schematic representation of the electrode's preparation (Fig. 1A, as described in section 2.2) shows all the active components of the N/G/Z/MCPE, the presence of which being detected by the EDX analysis (Fig. 1B, exhibiting components of $\mathrm{C}, \mathrm{O}, \mathrm{Al}$, Si and $\mathrm{F}$, with respective percentages of $38.9 \%, 21.3 \%, 8.2 \%, 17.3 \%$ and $14.2 \%$ ). 
(A)

Zeolite

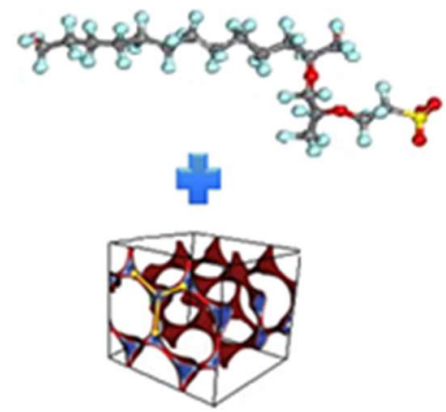

(B)

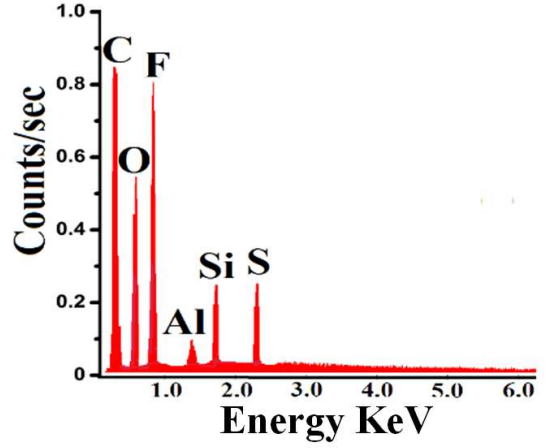

Graphene Oxide

Carbon paste electrode
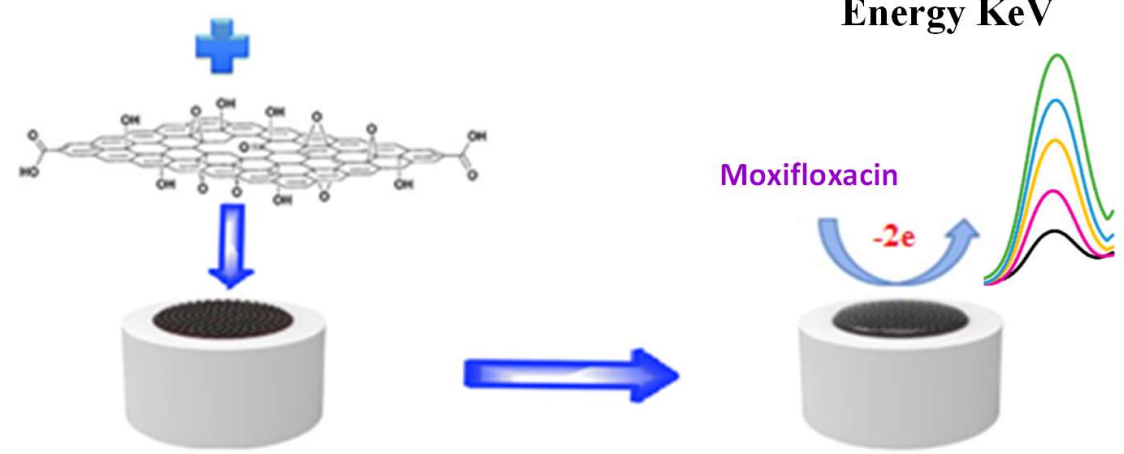

(C)
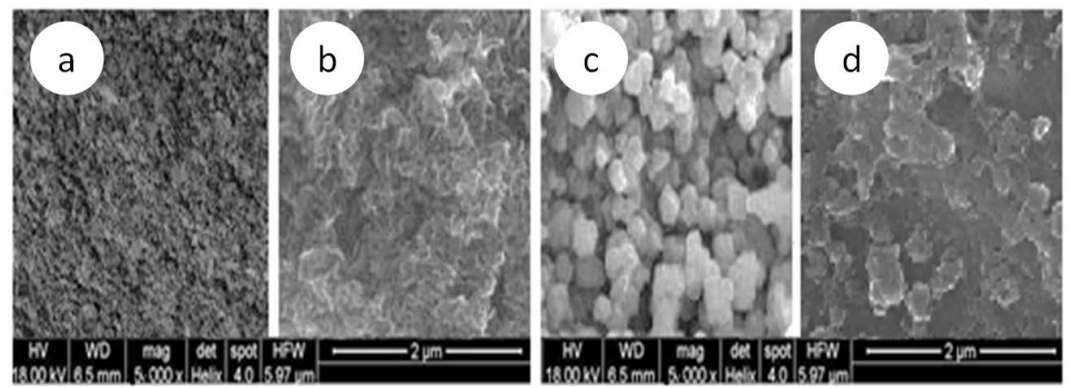

(D)

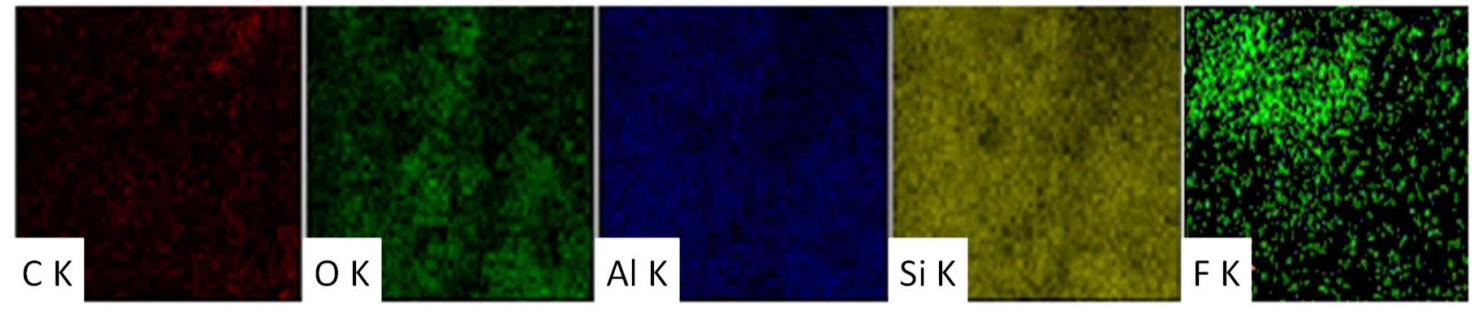

Figure 1. A) Schematic illustration of the N/G/Z/MCPE electrode preparation for MOXI detection; B) EDX spectra of N/G/Z/MCPE; C) SEM: a) Nafion, b) GO, c) zeolites and d) all components MCPE; D) Mapping EDX images for N/G/Z/MCPE (C, O, Al, Si and F elements). 
SEM imaging of CPE electrodes modified with a) Nafion, b) GO, c) zeolites and d) all components is depicted in Fig. 1C, showing a rough, featureless and compact surface in the presence of Nafion (a), randomly aggregated thin edged sheets of GO (b), while the presence of zeolites is visible from polycrystalline shiny aggregates (c); the image corresponding to the composite N/G/Z/MCPE material seeming to indicate a well distribution of zeolites (bright points) and GO with nafion and graphite paste (d), which is further confirmed by the EDX mapping images (see uniform distribution of C, O, Al, Si and F elements on Fig. 1D).

\subsection{Voltammetric behavior of Moxifloxacin Hydrochloride}

3.2.1. Influence of the electrode composition

Cyclic voltammetry (CV) was first used to select the most appropriate/sensitive sensor. CV curves recorded at a scan rate of $50 \mathrm{mV} / \mathrm{s}$ in a medium containing $1 \mathrm{mM}$ MOXI (in PBS, $\mathrm{pH}$ 7.4) have been compared (Fig. 2), using bare CPE (BCPE) or CPE modified with Nafion (N/MCPE), GO (G/MCPE), zeolite (Z/MCPE), GO + zeolite (G/Z/MCPE) and Nafion $+\mathrm{GO}+$ zeolite (N/G/Z/MCPE). Clearly, all modified electrodes gave rise to significant enhancement of signal intensity compared to the $\mathrm{BCPE}(62 \mu \mathrm{A}$ at $0.98 \mathrm{~V})$. The addition of each individual component (i.e., Nafion, GO and zeolite) caused low to moderate increases in the peak current intensity of MOXI at approximately the same potential values (i.e., N/MCPE (72 $\mu \mathrm{A}$ at $0.99 \mathrm{~V}), \mathrm{G} / \mathrm{MCPE}(98$ $\mu \mathrm{A}$ at $1.00 \mathrm{~V})$ and $\mathrm{Z} / \mathrm{MCPE}(114 \mu \mathrm{A}$ at $1.00 \mathrm{~V})$. Combination of several modifiers (i.e., GO + zeolite and especially Nafion $+\mathrm{GO}+$ zeolite) resulted in more dramatic improvements (i.e., G/Z/MCPE $(235 \mu \mathrm{A}$ at $0.98 \mathrm{~V})$ and N/G/Z/MCPE $(243 \mu \mathrm{A}, 1.01 \mathrm{~V}))$. The effect of Nafion and zeolite can be explained by their cation exchange ability, which is expected to accumulate the MOXI cation. Aluminum-rich zeolites (like zeolite Y) are hydrophilic and, when incorporated into 
CPE, such zeolite particles contributed to enhanced current responses by exposing larger CPE surface to the solution $[38,48]$. The role of GO is more expected to be related to its conductivity and unique electronic structure with high density of the electronic states and oxygenated edges known to accelerate the electron transfer processes $[32,49]$. All together, these cumulative effects led to the best performance for the electrode containing all the ingredients, and the oxidation signal of MOXI at N/G/Z/MCPE located at about $1.0 \mathrm{~V}$ was characterized by a current of $243 \mu \mathrm{A}$, about 4 times greater than that of the BCPE. This optimal signal was obtained at for an optimized paste composition; in particular, the sensitivity was function of the $\mathrm{GO} /$ zeolite ratio in the electrode. This has been evidenced by comparing the response of several N/G/Z/MCPE electrodes prepared from various contents of $\mathrm{GO}(0,5,10,15,20$ and $25 \mathrm{mg})$ and zeolites $(25,20,15,10,5$ and $0 \mathrm{mg})$, respectively, and recording CV curves in a medium containing $1 \mathrm{mM}$ MOXI, for which the highest current response was obtained for 15:15 GO/zeolite ratio (see inset in Fig. 2). Reproducibility of the proposed method has also been studied for five successive determinations of $1 \mathrm{mM}$ MOXI per day (intraday) and for 3 successive days (interday) using BCPE and N/G/Z/MCPE, respectively. The results (Table 1) indicates good reproducibility of the method, which was even slightly superior for $\mathrm{N} / \mathrm{G} / \mathrm{Z} / \mathrm{MCPE}$ in comparison to BCPE.

Table 1: Reproducibility of the proposed method using BCPE or N/G/Z/MCPE for the analysis of $1 \mathrm{mM}$ MOXI (intraday data obtained on the basis of 5 successive measurements; interday data based on 3 analyses (one each day) using the same electrode).

\begin{tabular}{|c|c|c|c|c|}
\hline Electrode & $\begin{array}{l}\text { Interday average } \\
\text { recovery \% }\end{array}$ & $\begin{array}{l}\text { Standard } \\
\text { deviation }\end{array}$ & $\begin{array}{l}\text { Intraday average } \\
\text { recovery \% }\end{array}$ & $\begin{array}{l}\text { Standard } \\
\text { deviation }\end{array}$ \\
\hline $\mathrm{BCPE}$ & 98.78 & \pm 2.44 & 98.25 & \pm 2.89 \\
\hline N/G/Z/MCPE & 100.32 & \pm 1.67 & 99.89 & \pm 1.92 \\
\hline
\end{tabular}




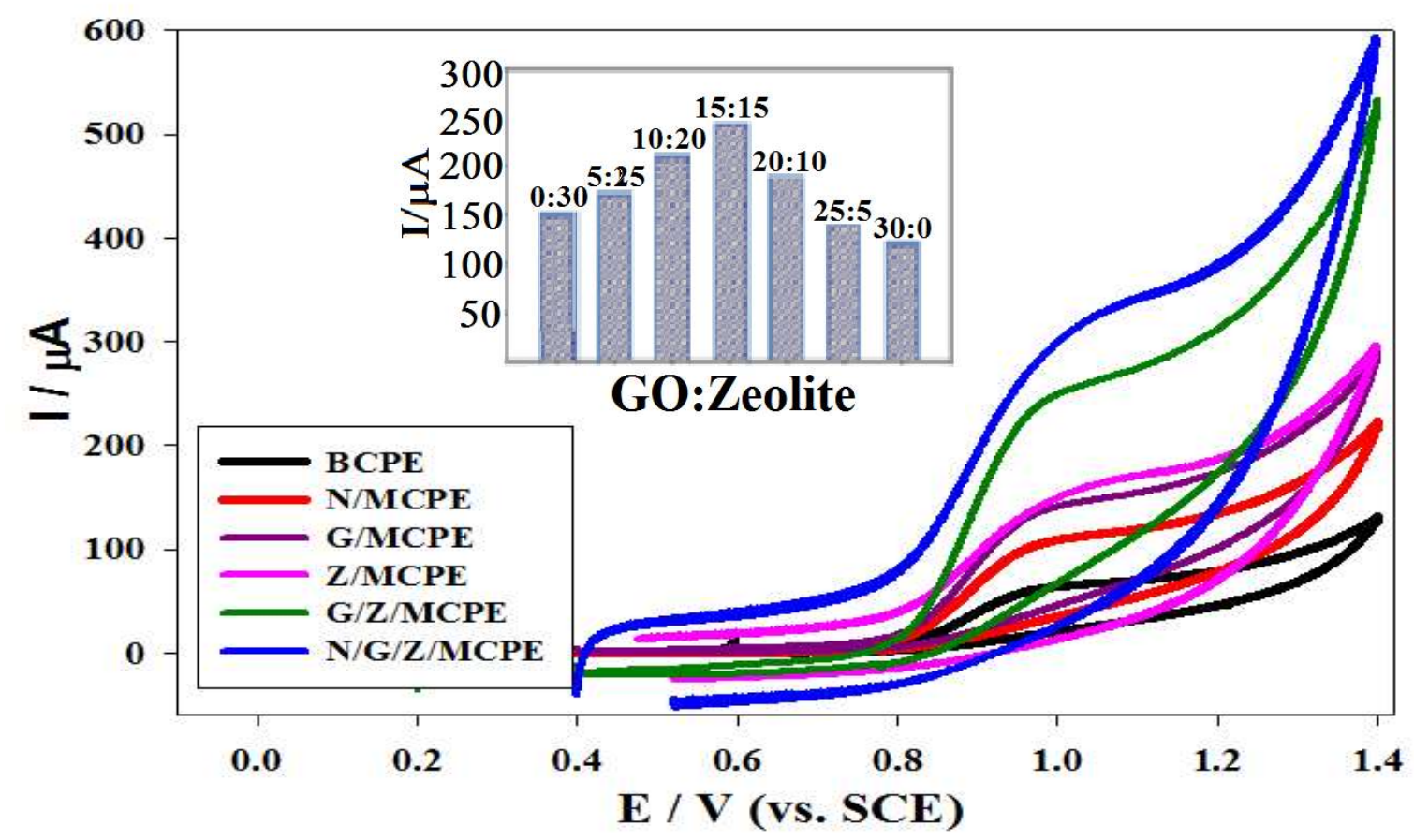

Figure 2. Cyclic voltammograms recorded in $1 \mathrm{mM}$ MOXI (in PBS, pH 7.4) at bare and modified CPE sensors, at a scan rate of $50 \mathrm{mV} / \mathrm{s}$. Inset: relation between the anodic signal intensity as a function of the GO:zeolite ratio in N/G/Z/MCPE.

\subsubsection{Effect of $\mathrm{pH}$}

The influence of $\mathrm{pH}$ of the medium on the CV response of MOXI was investigated in PBS (in the $\mathrm{pH}$ range $5.8-7.4)$ at $\mathrm{BCPE}$ and $\mathrm{N} / \mathrm{G} / \mathrm{Z} / \mathrm{MCPE}$. It shows a dependence in terms of both signal current and potential values (Fig. 3). The anodic peak potentials decreased linearly with $\mathrm{pH}(\mathrm{E}=$ $\left.1.45-0.062 \times \mathrm{pH}, \mathrm{r}^{2}=0.95\right)$ and the slope of $-62 \mathrm{mV} / \mathrm{pH}$ was close to the theoretical value characteristic for a $2 \mathrm{e}^{-} / 2 \mathrm{H}^{+}$reaction as expected for the oxidation of compounds of the floxacin family as MOXI is [50]. Also, the peak current increased with $\mathrm{pH}$, so that $\mathrm{pH} 7.4$ was chosen (corresponding to largest current response) was chosen for further experiments. 


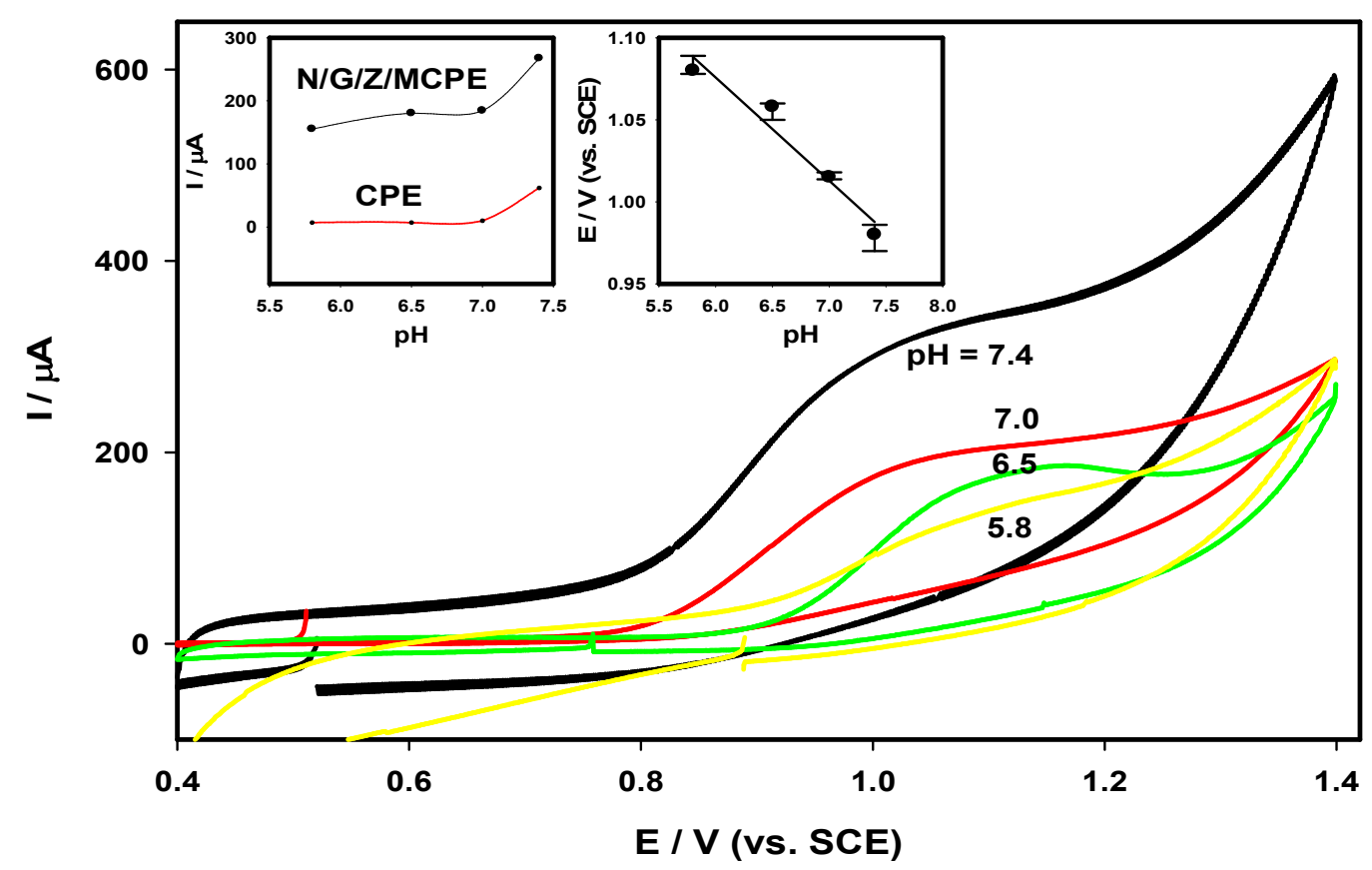

Figure 3. Cyclic voltammograms of $1 \mathrm{mM}$ MOXI in PBS adjusted at various $\mathrm{pH}$ values, recorded at a scan rate $50 \mathrm{mV} / \mathrm{s}$ using N/G/Z/MCPE. Insets: (left) variation of anodic signal intensity with $\mathrm{pH}$, at bare $\mathrm{CPE}$ and $\mathrm{N} / \mathrm{G} / \mathrm{Z} / \mathrm{MCPE}$; (right) variation of anodic peak potential with $\mathrm{pH}$ for N/G/Z/MCPE.

\subsubsection{Effect of potential scan rate}

Varying the potential scan rate ( $v$ ranging from 10 to $100 \mathrm{mV} / \mathrm{s}$ ) for the analysis of $1 \mathrm{mM}$ MOXI by CV led to larger current intensities when increasing scan rates (see Fig. S1 in supporting information). A linear relationship between the logarithm of the anodic peak current and that of the scan rate was obtained as shown in the top left inset of the figure, with the following equation: $\log \operatorname{Ip}(\mu \mathrm{A})=1.13+0.76 \times \log v\left(\mathrm{r}^{2}=0.997\right)$. This indicated that the oxidation process of MOXI is an adsorption-diffusion process [51]. The existence of adsorption is also pointed out by the linear relationship observed between the anodic peak current and the scan rate (top right of the figure). 
The active surface area of both BCPE and N/G/Z/MCPE electrodes was estimated from the Randles-Sevcik equation (1) [51] using a redox probes $\left(\mathrm{K}_{4} \mathrm{Fe}(\mathrm{CN})_{6}\right)$ behaving under diffusion control (i.e., linear variation of the $\mathrm{I}_{\mathrm{P}}$ versus $v^{1 / 2}$ plot) for a known concentration of $\mathrm{K}_{4} \mathrm{Fe}(\mathrm{CN})_{6}$, based on:

$\mathrm{I}_{\mathrm{p}}=2.69 \times 10^{5} \mathrm{n}^{3 / 2} \mathrm{AD}^{1 / 2} v^{1 / 2} \mathrm{C}$

Where Ip is the peak current (A), $\mathrm{n}$ is the number of electrons transferred, $v$ is the scan rate $(\mathrm{V} / \mathrm{s})$, $\mathrm{D}$ the diffusion coefficient, $\mathrm{A}$ is the area of the electrode and $\mathrm{C}$ is the concentration of $\mathrm{K}_{4} \mathrm{Fe}(\mathrm{CN})_{6}$. For $1.0 \mathrm{mmol} \mathrm{L}^{-1} \mathrm{~K}_{4} \mathrm{Fe}(\mathrm{CN})_{6}$ (in $0.10 \mathrm{~mol} \mathrm{~L}^{-1} \mathrm{KCl}$ electrolyte), with $\mathrm{n}=1$ and $\mathrm{D}=7.6 \times 10^{-6} \mathrm{~cm} \mathrm{~s}^{-1}$, one can get the A values from the measured slopes of the IP versus $v^{1 / 2}$ plots. The calculated active surface areas (A values) were respectively 0.07 and $0.147 \mathrm{~cm}^{2}$ for BCPE and N/G/Z/MCPE. Comparing this enhancement in the surface area by a factor two to the 4-times increase in peak currents for MOXI when passing from BCPE to N/G/Z/MCPE further confirms the accumulation and/or faster electron transfer kinetics at the modified electrode.

\subsubsection{Response stability and effect of accumulation time}

Using the same $\mathrm{N} / \mathrm{G} / \mathrm{Z} / \mathrm{MCPE}$ electrode for successive measurements of $1 \mathrm{mM}$ MOXI by multisweep CV (see Fig. S2A in supporting information), a rather stable response was observed as the anodic current only lost $14 \%$ of its original value after a number of 100 consecutive cycles. This satisfactory stability of $\mathrm{N} / \mathrm{G} / \mathrm{Z} / \mathrm{MCPE}$ is most probably due to the permselective barrier offered by Nafion, protecting the electrode surface against gradual fouling by the anodic degradation products [52]. Thus, in this work, no need to change the electrode between each experiment as it was necessary for our previous sensor [26]. The influence of soaking time at open circuit in the MOXI solution (1 mM in PBS pH 7.4) was also investigated by CV (see Fig. S2B in 
supporting information): $83 \%$ of the maximal current values was reached without preconcentration and then the signal further increased with the accumulation time up to $90 \mathrm{~s}$ to finally level off at longer times. This value of $90 \mathrm{~s}$ was thus chosen as the optimal one corresponding to the initial stage of steady-state.

\subsubsection{Additional observations}

Electrochemical impedance spectroscopy (EIS) enables to examine the conductivity properties of the modified sensor. By comparing EIS data for bare and N/G/Z/MCPE electrodes (see Fig. S3 in supporting information), one can see Nyquist plots consisting of two semicircles connected to each other, agreeing with a model of two time constants $[53,54]$. They consist in a small depressed semicircle curve at high frequency associated with a larger semicircle at low frequency, suggesting a charge-transfer mechanism based on adsorption with some diffusion contribution, consistent with the effect of potential scan rate discussed above (section 3.2.3). The best equivalent circuit utilized for fitting $[55,56]$ is also shown as inset (Fig. S3). It comprises $\mathrm{R}_{\mathrm{s}}$ (solution resistance), $\mathrm{R}_{\mathrm{CT}}$ (Charge transfer resistance), $\mathrm{W}$ (Warburg impedance linked to diffusion process) and $\mathrm{Q}_{\mathrm{dl}}$ (constant phase element of double layer capacitance) which is presented to validate the surface non-uniformity, $Z_{\mathrm{CPE}}=\left[C(\mathrm{j} \omega)^{\alpha}\right]^{-1}$, where $\alpha$ related to non-uniformity, $\mathrm{j}$ is the imaginary number $\left(\mathrm{j}^{2}=-1\right), \omega=2 \pi f\left(\operatorname{rad~s}^{-1}\right)$ and $\mathrm{f}(\mathrm{Hz})$ is the frequency. $\mathrm{Q}_{\mathrm{m}}$ is constant phase element of metal capacitance and $R_{m}$ is metal resistance. N/G/Z/MCPE demonstrates a large capacitance $\left(18.5 \mu \mathrm{F} \mathrm{cm}^{-2}\right)$ and Warburg impedance $\left(1.02 \mathrm{k} \Omega \mathrm{cm}^{2} \mathrm{~s}^{-1 / 2}\right)$ while keeping low $\mathrm{R}_{\mathrm{CT}}$ $\left(2.3 \mathrm{k} \Omega \mathrm{cm}^{2}\right)$, which indicates a better conductivity compared to bare electrode (capacitance $=1.5$ $\mu \mathrm{F} \mathrm{cm}{ }^{-2}, \mathrm{~W}=42 \Omega \mathrm{cm}^{2} \mathrm{~s}^{-1 / 2}$ and $\mathrm{R}_{\mathrm{CT}}=11.53 \mathrm{k} \Omega \mathrm{cm}^{2}$ ). These is due to the presence of $\mathrm{GO}$ in the 
composite electrode, which is expected to facilitate electron transfer processes and to provide a larger electroactive surface area to N/G/Z/MCPE compared to BCPE.

Quantum chemistry computational simulation was also performed to get additional information. Theoretical calculations were achieved with Density Functional Theory (DFT) in grouping with the B3LYP functional (DFT-B3LYP). The base set utilized is $6-311++\mathrm{G}(\mathrm{d}, \mathrm{p})$ to explore the addition impact of diffuse orbitals on the calculated molecular parameters. The following values were obtained for the highest occupied molecular orbital energy $\left(\mathrm{E}_{\mathrm{HOMO}}=-7.790\right.$ $\mathrm{eV})$, the lowest unoccupied molecular orbital energy $\left(\mathrm{E}_{\mathrm{LUMO}}=-1.489 \mathrm{eV}\right)$ and dipole moment $(\mu$ $=9.685$ Debye). Optimized structures and frontier molecular orbital density distributions (HOMO \& LUMO) of MOXI obtained by 6-311++G(d,p) are shown in Figure 4. The HOMO orbitals are located on $\mathrm{N}$ atoms, legitimizing the mechanism reported for structurally-related compounds [50], whereas The LUMO is located on a stable aromatic ring explaining why no reduction of MOXI can be observed.

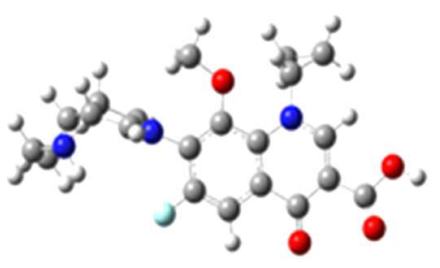

Moxifloxacin

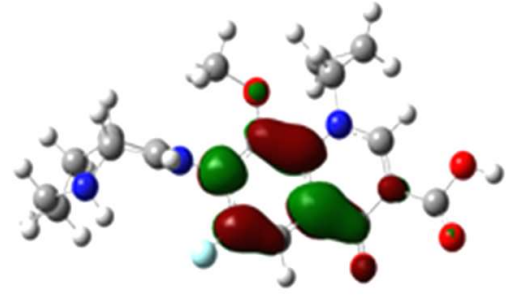

LUMO

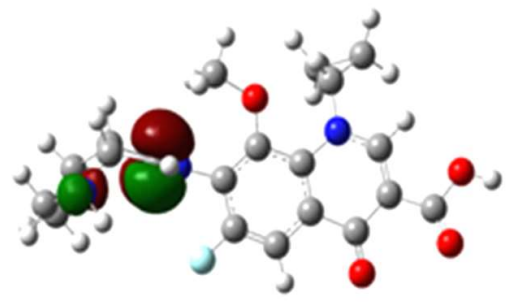

HONO

Figure 4. Optimized structure and frontier molecular orbital density (HOMO and LUMO) of Moxifloxacin drug. 


\subsection{Electrochemical sensing of Moxifloxacin Hydrochloride}

\subsubsection{Detection by chronoamperometry}

The chronoamperometric curves for MOXI at various concentrations $(0.04-250 \mu \mathrm{M})$, as recorded at a constant potential $(+1.01 \mathrm{~V}$ vs. SCE) utilizing N/G/Z/MCPE sensor in PBS $(\mathrm{pH}=$ 7.4), are depicted in Figure 5. They show a typical Cottrellian behavior and a linear variation of currents sampled at a fixed time as short as 1 second can be obtained (see inset in Fig. 5) [57], obeying to the equation: $\operatorname{Ip}(\mu \mathrm{A})=0.109 \mathrm{C}+15.1$ with a correlation coefficient of 0.985 . Note that background currents (i.e., observed in the absence of MOXI) at such short sampling time are quite large, resulting in high intercept in the calibration curve and making detection by CA not so appropriate.

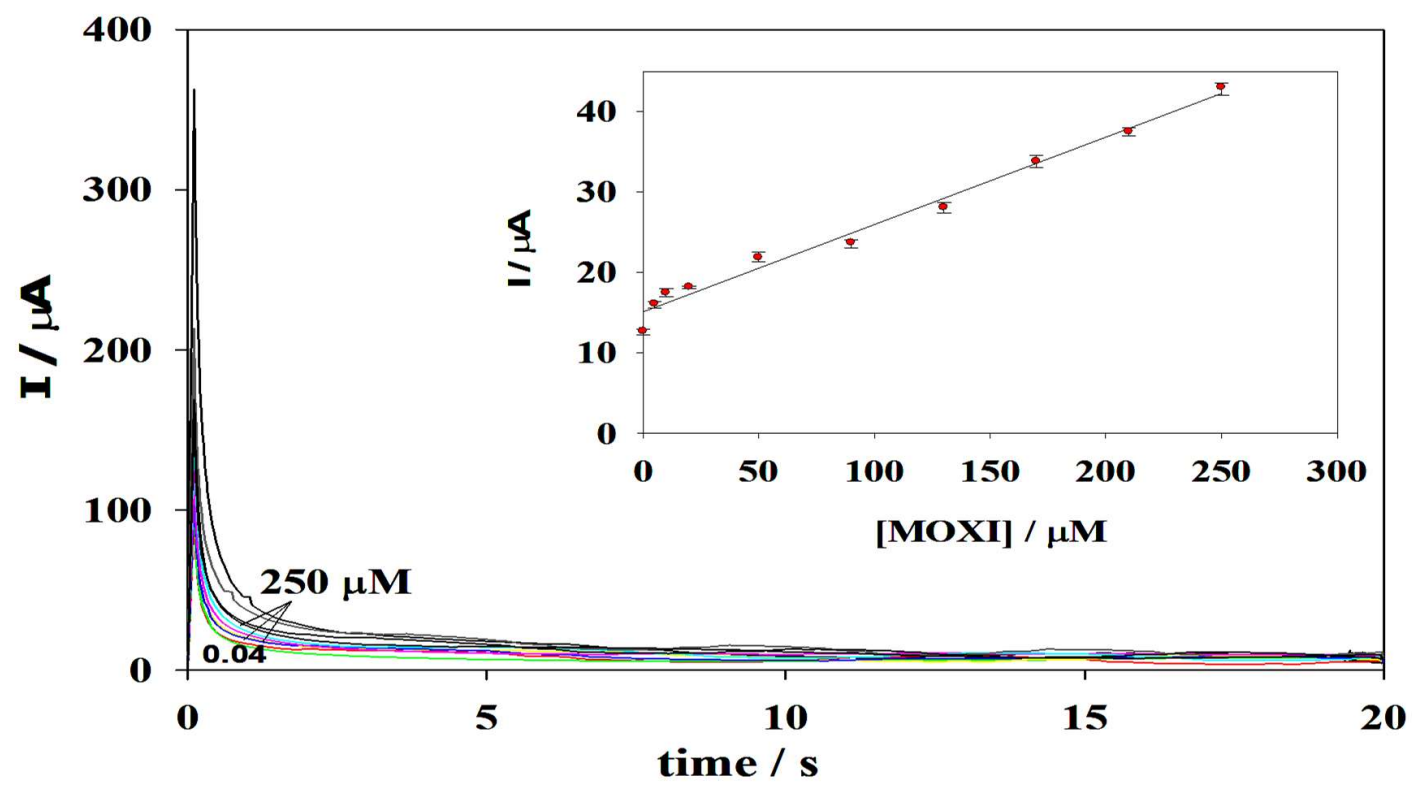

Figure 5: Chronoamperograms obtained at N/G/Z/MCPE in PBS ( $\mathrm{pH}$ 7.4) using different concentrations of MOXI $(0.04-250 \mu \mathrm{M})$; inset: corresponding calibration curve built from using currents sampled at $1 \mathrm{~s}$. 
The transient current decay with time for electro-oxidation of MOXI follows the equation $\mathrm{I}=\mathrm{nF} \mathrm{A} \mathrm{D}{ }^{1 / 2} \mathrm{C}^{-1 / 2} \mathrm{t}^{-1 / 2}$, where $\mathrm{I}$ is the transient current $(\mu \mathrm{A}), \mathrm{A}$ is the electrode area $\left(\mathrm{cm}^{2}\right), \mathrm{C}$ is the analyte concentration $\left(\mathrm{mol} \mathrm{L}^{-1}\right)$ and $\mathrm{D}$ is the diffusion coefficient $\left(\mathrm{cm}^{2} \mathrm{~s}^{-1}\right)$. For all MOXI concentrations, the current variations versus $\mathrm{t}^{-1 / 2}$ are linear (see Fig. S4A in supporting information), confirming the Cottrellian behavior. Plotting their slopes with respect to MOXI concentration (see Fig. S4B in supporting information) can be exploited to estimate the diffusion coefficient (D), which is evaluated here as $6.2 \times 10^{-7} \mathrm{~cm}^{2} \mathrm{~s}^{-1}$.

\subsubsection{Detection by EIS}

The above EIS characterization (section 3.2.5) is not only useful to point out the adsorptiondiffusion process operating at the N/G/Z/MCPE electrode, but the data can be also used for MOXI sensing. This is shown in Figure 6 where the Nyquist plots vary with MOXI concentration. A linear calibration curve can be obtained by plotting the impedance values obtained at the modified $\mathrm{N} / \mathrm{G} / \mathrm{Z} / \mathrm{MCPE}$ electrode related to that of $\mathrm{BCPE}$ (i.e., $\mathrm{R}_{\mathrm{CT}}-\mathrm{R}^{\mathrm{o}} \mathrm{CT}$ values) as a function of MOXI concentration (see inset in Fig. 6). The corresponding linear variation is expressed as $\mathrm{R}_{\mathrm{CT}}-\mathrm{R}^{\mathrm{o}} \mathrm{CT}$ $(\mathrm{ohm})=6.0 \mathrm{C}-7890$, with a correlation coefficient of 0.989 . EIS exhibits a calibration curve in a concentration range comparable to that achievable by $\mathrm{CA}$. 


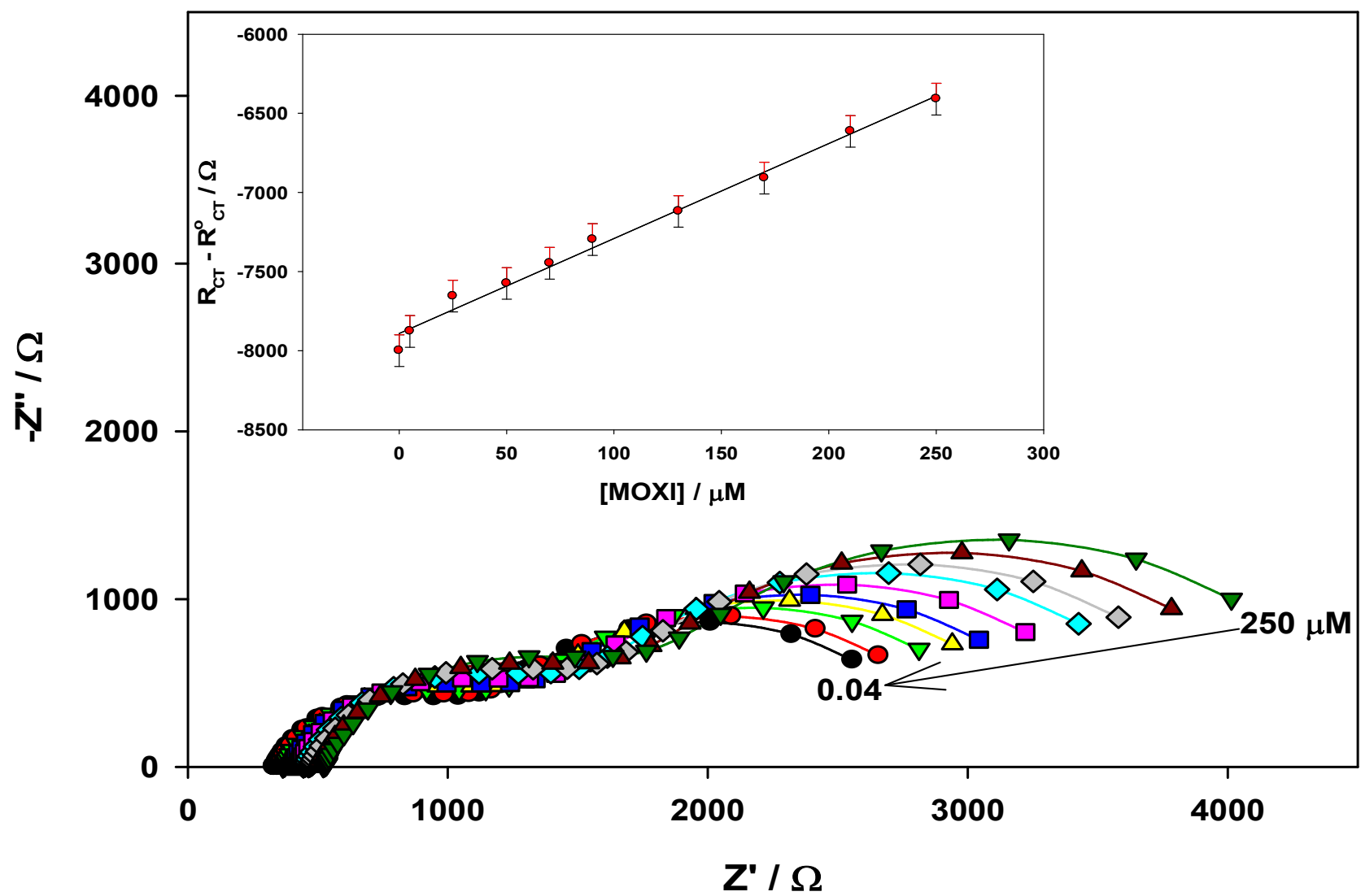

Figure 6. The Nyquist plots for N/G/Z/MCPE in the presence of increasing concentrations of MOXI (from 0.04 to $250 \mu \mathrm{M}$ ); inset shows the corresponding calibration curve.

\subsubsection{Detection by DPV and analytical characteristics}

Pulsed electrochemical methods such as differential pulse or square wave voltammetry are often used as sensitive techniques in various detection schemes at modified electrodes [58-60]. DPV was applied here for the determination of MOXI (in the concentration range from $4.0 \times 10^{-8}$ to $2.5 \times 10^{-4} \mathrm{M}$ ) after $90 \mathrm{~s}$ accumulation (under stirring) and the data are shown in Figure 7 . The parameters for DPV were $25 \mathrm{~ms}$ pulse width and $200 \mathrm{~ms}$ pulse period. The sensor exhibited a linear response over the whole concentration range, characterized by the following equation: 
$\operatorname{Ip}(\mu \mathrm{A})=0.028 \mathrm{C}+1.47$, with a correlation coefficient of 0.999 . The limit of detection (LOD) and limit of quantification (LOQ) were calculated according to the IUPAC recommendations utilizing the following equations: $\mathrm{LOD}=3 \mathrm{~s} / \mathrm{m}$ and $\mathrm{LOQ}=10 \mathrm{~s} / \mathrm{m}$, where $\mathrm{s}$ is the standard deviation and $\mathrm{m}$ is the slope of the calibration curves. They were found to be $1.0 \mathrm{nM}$ and $3.3 \mathrm{nM}$, respectively.

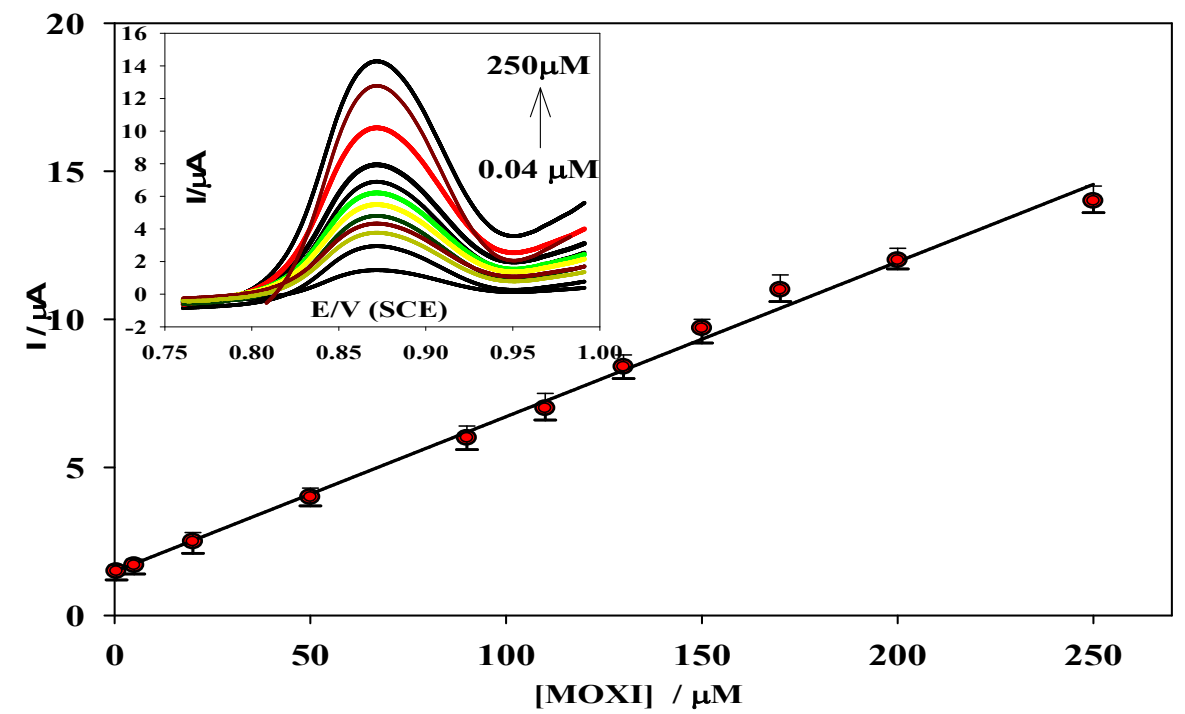

Figure 7. DPV curves recorded for successive additions of MOXI in PBS (pH 7.4) using the N/G/Z/MCPE (inset) et corrsponding calibration plot.

The proposed electrochemical method for MOXI detection using N/G/Z/MCPE is compared with some recent approaches based on spectrophotometry, potentiometry or other electrochemical methods, in terms of sensitivity, linear range and detection limit (see Table S1 in supporting information). It indicates at least comparable and most often better performance, notably through its low LOD (1.0 $\mathrm{nM})$ and high sensitivity $\left(2.8 \times 10^{-4} \mu \mathrm{A} / \mathrm{M}\right)$.

3.3.4. Analysis of MOXI in urine medium 
The applicability of the proposed method for the determination of MOXI in real samples was demonstrated via its analysis in urine. The calibration curve obtained with N/G/Z/MCPE in urine sample spiked with MOXI (see Fig. S5 in supporting information) gave a linear correlation over a concentration range of $20-200 \mu \mathrm{M}\left(\operatorname{Ipa}(\mu \mathrm{A})=0.031 \times \mathrm{C}(\mu \mathrm{M})+3.62, \mathrm{r}^{2}=0.96\right)$. The LOD was $8.9 \mathrm{nM}$, and the LOQ was $29.6 \mathrm{nM}$, i.e., one order of magnitude larger than in pure water but still attractive values. To point out the accuracy and precision of the method, 4 different concentrations were selected on the calibration plot and everyone was repeated five times, showing excellent recovery and very good reproducibility (Table 2).

Table 2. The accuracy and precision of the proposed electrode for detecting MOXI in urine sample.

\begin{tabular}{llllll}
\hline $\begin{array}{l}\text { Spiked } \\
{[\mathbf{M O X I}]}\end{array}$ & $\begin{array}{l}\text { Detected } \\
{[\mathbf{M O X I}]^{\mathbf{a}}}\end{array}$ & $\mathbf{( \% )}$ & $\mathbf{\%}$ & $\mathbf{S E}^{\mathbf{b}}$ & $\mathbf{C L}^{\mathbf{c}}$ \\
$(\boldsymbol{\mu M})$ & $(\boldsymbol{\mu M})$ & & $(\boldsymbol{\mu M})$ & $(\boldsymbol{\mu M})$ \\
\hline 12.5 & 12.4 & 99.4 & 3.0 & 1.5 & 0.1 \\
25.0 & 24.9 & 99.6 & 1.5 & 1.1 & 0.3 \\
50.0 & 49.8 & 99.6 & 2.6 & 0.5 & 0.6 \\
100.0 & 100.6 & 100.6 & 4.0 & 1.1 & 1.1
\end{tabular}

${ }^{a}$ Five measurements, ${ }^{b}$ Standard error $(\mathrm{SE})=\mathrm{SD} / \sqrt{ } \mathrm{n}$ and ${ }^{\mathrm{c}} 95 \%$ confidence level $(\mathrm{CL})$

\subsubsection{Simultaneous detection of MOXI and Paracetamol}

Although the metabolism of paracetamol can be decreased when combined with MOXI, if you need a pain killer it is however fine to take paracetamol with MOXI. For example, patients receiving $200 \mathrm{mg}$ MOXI orally each half day could also take $500 \mathrm{mg}$ paracetamol in case of dry cough and high fever rate [10]. So, the simultaneous detection of MOXI and paracetamol is of interest. By varying the concentration of both drugs in 2:5 ratio in PBS (pH 7.4), good calibration 
curves for both drugs can be obtained from DPV utilizing N/G/Z/MCPE (Figure 8, insets). The data also indicate a clear separation between the DPV peaks characteristic of each drug, with the detection of paracetamol at $+0.66 \mathrm{~V}$ and MOXI at $+0.84 \mathrm{~V}$ (i.e., corresponding to a $\Delta \mathrm{E}$ value of $0.18 \mathrm{~V})$. This confirms the possibility of the proposed method to detect simultaneously both drugs when present in the same medium.

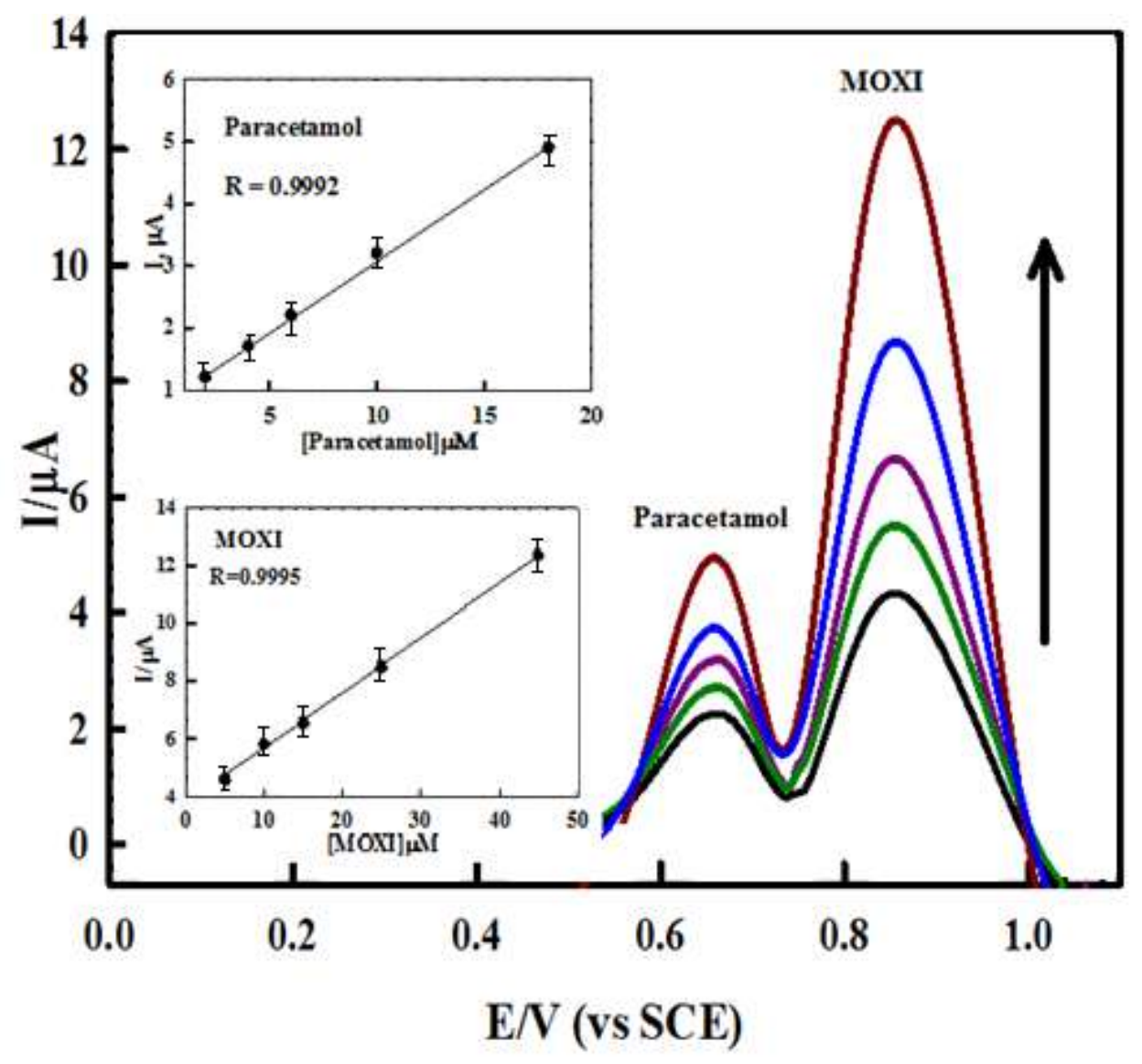

Figure 8. Simultaneous detection of MOXI (in the concentration range varying from $5 \times 10^{-6} \mathrm{M}$ to $\left.4.5 \times 10^{-5} \mathrm{M}\right)$ and paracetamol $\left(2 \times 10^{-6} \mathrm{M}\right.$ to $\left.1.8 \times 10^{-5} \mathrm{M}\right)$ using N/G/Z/MCPE. 


\section{Conclusions}

A novel, stable and simple electrochemical sensor with excellent performance for the detection of Moxifloxacin Hydrochloride has been elaborated from a carbon paste electrode modified with Nafion, GO and zeolite particles (N/G/Z/MCPE). The additional properties of these modifiers enabled to get better performance in comparison to bare carbon paste electrode, and this can be exploited for sensing MOXI by CA, EIS or DPV. DPV exhibited the best results, with fast response time (90 s), high sensitivity $\left(2.8 \times 10^{-4} \mu \mathrm{A} / \mathrm{M}\right)$, low detection limit $(1.0 \mathrm{nM})$ and a limit of qualification of $3.3 \mathrm{nM}$. Contrary to related MCPE sensors based on metal nanoparticles electrocatalysts, the present $\mathrm{N} / \mathrm{G} / \mathrm{Z} / \mathrm{MCPE}$ offers the possibility of successive measurements without the need to renew the electrode surface. MOXI can be detected in the presence of the coadministrated drug paracetamol, thanks to well separated DPV peaks $(\Delta \mathrm{E}=0.18 \mathrm{~V})$. This sensor is also applicable for MOXI detection in urine samples, with recovery values of $99.4-100.6 \%$ and RSD values ranging from 1.5 to $4 \%$, ensuring a good precision of the proposed method.

Acknowledgement: A.M.F. acknowledges a financial support from the Egypt-France Cooperation Program (STDF-IFE).

Conflict of interest: no conflict of interest.

Competing interests: no competing interests.

Declarations of interest: none.

Data availability statement: The raw/processed data required to reproduce these findings cannot be shared at this time as the data also forms part of an ongoing study. 


\section{References}

[1] I.C. Gyssens, M. Dryden, P. Kujath, D. Nathwani, N. Schaper, B. Hampel, P. Reimnitz, J. Alder, P. Arvis, A randomized trial of the efficacy and safety of sequential intravenous/oral moxifloxacin monotherapy versus intravenous piperacillin/tazobactam followed by oral amoxicillin/clavulanate for complicated skin and skin structure infections, $J$ Antimicrob Chemother. 2011, 66, 2632.

[2] K. Rudnicki, L. Poltorak, S. Skrzypek, E.J.R. Sudhölter, Ion transfer voltammetry for analytical screening of fluoroquinolone antibiotics at the water-1.2-dichloroethane interface, Anal. Chim. Acta 2019, 1085, 75.

[3] S. Kim, D. Aga, Potential ecological and human health impacts of antibiotics and antibioticresistant bacteria from wastewater treatment plants, J. Toxicol. Environ. Health B-Crit. Rev. 2007, 10, 559-573.

[4] K. Kummerer, Significance of antibiotics in the environment, J. Antimicrob. Chemother. 2003, $52,5$.

[5] R. Mangukiya, R. Patel, P. Shah, K. Patel, Chromatographic methods for simultaneous determination of moxifloxacin hydrochloride and difluprednate in ophthalmic dosage form, Acta Chrom. 2015, 27, 495.

[6] N. Reddy, T. Samidha, E. Sushma, P. Sagar, D. Sudheerkumar, G. Sreekanth, Simple RPHPLC method development and validation for simultaneous estimation of Moxifloxacin hydrochloride and Bromofenac sodium on eye drops, Int. J. Pharm. Pharm. Sci. 2013, 5, 689. 
[7] A. Patel Ronak, B. Mayank, K. Brahmbhatt, C. Patel, S. Shah, Development and validation of RP-HPLC method for estimation of cefiximetrihydrate and moxifloxacin hydrochloride in pharmaceutical dosage form. Pharma Sci. Monitor 2012, 3, 155.

[8] L.A. Cruz, R. Hall, Enantiomeric purity assay of moxifloxacin hydrochloride by capillary electrophoresis, J. Pharm. Biomed. Anal. 2005, 38, 8.

[9] S. Ashour, R. Bayram, Development and validation of sensitive kinetic spectrophotometric method for the determination of moxifloxacin antibiotic in pure and commercial tablets, Spectrochim. Acta A 2015, 140, 216.

[10] R. Mandavia, M. Virpariya, T.K. Patel, C. Tripathi, Moxifloxacin-induced hypoglycemia in a non-diabetic patient, Curr. Drug Safety 2012, 7, 183.

[11] N. Pradhan, H. Rajkhowa, H. Giri, B. Shrestha, Simultaneous Spectrophotometric Estimation of Moxifloxacin Hydrochloride and Doxorubicin Hydrochloride, Int. J. Pharm. Pharm. Sci. 2015, $7,21$.

[12] M. Shehata, A.M. Fekry, A. Walcarius, Moxifloxacin Hydrochloride Electrochemical Detection at Gold Nanoparticles Modified Screen-Printed Electrode, Sensors 2020, 20, 2797.

[13] G. Maduraiveeran, M. Sasidharan, V. Ganesan, Electrochemical sensor and biosensor platforms based on advanced nanomaterials for biological and biomedical applications, Biosens. Bioelectron. 2018, 103, 113.

[14] S.M. Azab, M. Shehata, A.M. Fekry, A novel electrochemical analysis of the legal psychoactive drug caffeine using zeolites/MWCNT modified carbon paste sensor, New J. Chem. 2019, 43, 15359. [15] M.M. Hefnawy, A.M. Homoda, M.A. Abounassif, A.M. Alanazi, A. Al-Majed, G.A. Mostafa, Potentiometric determination of moxifloxacin in some pharmaceutical formulation using PVC membrane sensors, Chem. Cent. J. 2014, 8,1 . 
[16] M.R. Elghobashy and M.R. Rezk, Comparative Study of Different Ionophores in Ion Selective Electrodes for Stability indicating Determination of Moxifloxacin, Anal. Bioanal. Electrochem. 2014, 6,461 .

[17] Q. Zhou, N. Long, L. Liu, H. Zhai, M. Zhu, Electrochemical determination of moxifloxacin hydrochloride based on molecularly imprinted polymer modified carbon paste electrode, Int. J. Electrochem. Sci. 2015, 10, 5069.

[18] I. Svancara, K. Kalcher, A. Walcarius, K. Vytras, Electroanalysis with Carbon Paste Electrodes, Analytical Chemistry Series, CRC Press, Boca Raton, FL, USA, 2012.

[19] K. Kalcher, I. Svancara, M. Buzuk, K. Vytras, A. Walcarius, Electrochemical sensors and biosensors based on heterogeneous carbon materials, Monatsh. Chem. 2009, 140, 861 .

[20] D.B. Shikandar, N.P. Shetti, R.M. Kulkarni, S.D. Kulkarni, Silver-doped titania modified carbon electrode for electrochemical studies of furantril, ECS J. Solid State Sci. Technol. 2018, 7, Q3215.

[21] G. Manasa, R.J. Mascarenhas, B.M. Basavaraja, Sensitively-selective determination of Propyl Paraben preservative based on synergistic effects of polyaniline-zinc-oxide nano-composite incorporated into graphite paste electrode, Colloids Surf. B 2019, 184, 110529.

[22] O.J. D'Souza, R.J. Mascarenhas, A.K. Satpati, I.N.N. Namboothiri, S. Detriche, Z. Mekhalif, J. Delhalle, A multi-walled carbon nanotube/poly-2,6-dichlorophenolindophenol film modified carbon paste electrode for the amperometric determination of L-tyrosine, $R S C A d v . \mathbf{2 0 1 5}, 5,91472-91481$.

[23] G. Manasa, R.J. Mascarenhas, A.K. Satpati, B.M. Basavaraja, S. Kumar, An electrochemical Bisphenol $\mathrm{F}$ sensor based on $\mathrm{ZnO} / \mathrm{G}$ nano composite and $\mathrm{CTAB}$ surface modified carbon paste electrode architecture, Colloids Surf. B 2018, 170, 144. 
[24] S.D. Bukkitgar, N.P. Shetti, R.M. Kulkarni, S.B. Halbhavi, M. Wasim, M. Mylar, P.S. Durgi, S.S. Chirmure, Electrochemical oxidation of nimesulide in aqueous acid solutions based on $\mathrm{TiO}_{2}$ nanostructure modified electrode as a sensor, J. Electroanal. Chem. 2016, 778, 103.

[25] O.J. D'Souza, R.J. Mascarenhas, A.K. Satpati, V. Mane, Z. Mekhalif, Application of a Nanosensor Based on MWCNT-Sodium Dodecyl Sulphate Modified Electrode for the Analysis of a Novel Drug, Alpha-Hydrazinonitroalkene in Human Blood Serum, Electroanalysis 2017, 29, 1794.

[26] A.M. Fekry, A new simple electrochemical Moxifloxacin Hydrochloride sensor built on carbon paste modified with silver nanoparticles, Biosens. Bioelectron. 2017, 87, 1065.

[27] Z. Bo, X. Shuai, S. Mao, H. Yang, J. Qian, J. Chen, J. Yan, K.J.S.R. Cen, Green preparation of reduced graphene oxide for sensing and energy storage applications, Sci. Rep. 2014, 4, 4684.

[28] W. Chen, L.J.N. Yan, Preparation of graphene by a low-temperature thermal reduction at atmosphere pressure, Nanoscale 2010, 2, 559.

[29] Y. Zhang, Q. Wan, N. Yang, Recent Advances of Porous Graphene: Synthesis, Functionalization, and Electrochemical Applications, 1903780.

[30] H.H. Rao, Z.H. Xue, X.M. Wang, G.H. Zhao, H.H. Hou, H. Wang, Electrochemical Sensors Based on Electrochemically Reduced Graphene Oxide, Prog. Chem. 2016, $28,337$.

[31] S. Kumar, S.D. Bukkitgar, S. Singh, V. Singh, K.R. Reddy, N.P. Shetti, C.V. Reddy, V. Sadhu, S.J.C. Naveen, Electrochemical Sensors and Biosensors Based on Graphene Functionalized with Metal Oxide Nanostructures for Healthcare Applications, ChemistrySelect 2019, 4, 5322 . 
[32] N.P. Shetti, D.S. Nayak, S.J. Malode, R.M. Kulkarni, D.B. Kulkarni, R.A. Teggi, V.V. Joshi, Electrooxidation and determination offlufenamic acid at graphene oxide modified carbon electrode, Surf. Interfaces 2017, 9, 107.

[33] O.J. D’Souza, R.J. Mascarenhas, A.K. Satpati, B.M Basavaraja, A novel ZnO/reduced graphene oxide and Prussian blue modified carbon paste electrode for the sensitive determination of Rutin, Sci. China Chem. 2019, 62, 262.

[34] C.M. Lew, R. Cai, Y. Yan, Zeolite thin films: from computer chips to space stations, Acc. Chem. Res. 2010, 43, 210.

[35] A. Walcarius, Zeolite-modified electrodes in electroanalytical chemistry, Anal. Chim. Acta 1999, $384,1$.

[36] A. Walcarius, Electroanalytical applications of microporous zeotites and mesoporous (Organo) silicas: Recent trends, Electroanalysis 2008, 20, 711.

[37] L. Siara, F. De Lima, C. Cardoso, G. Arruda, Electrochemically pretreated zeolite-modified carbon-paste electrodes for determination of linuron in an agricultural formulation and water, Electrochim. Acta 2015, 151, 609.

[38] J. Wang, A. Walcarius, Zeolite containing oxidase-based carbon paste biosensors, $J$. Electroanal. Chem. 1996, 404, 237.

[39] A. Walcarius, T. Barbaise, J. Bessière, Factors affecting the analytical applications of zeolitemodified electrodes - Preconcentration of electroactive species, Anal. Chim. Acta 1997, 340, 61. [40] A. Walcarius, Factors affecting the analytical applications of zeolite modified electrodes: indirect detection of nonelectroactive cations, Anal. Chim. Acta 1999, 388, 79. 
[41] M.L. Hamlaoui, K. Reybier, M. Marrakchi, N. Jaffrezic-Renault, C. Martelet, R. Kherrat, A. Walcarius, Development of a urea biosensor based on a polymeric membrane including zeolite, Anal. Chim. Acta 2002, 466, 39.

[42] C. H. Park, C. H. Lee, M. D. Guiver, Y. M. Lee, Sulfonated hydrocarbon membranes for medium-temperature and low-humidity proton exchange membrane fuel cells (PEMFCs), Prog. Polym. Sci. 2011, 36, 1443.

[43] H. Li, R. Ge, E. Wang, Catalytic oxidation and flow detection of acetaminophen at a dicyanobis (1, 10-phenanthroline) iron (II)-modified electrode, Anal. Chim. Acta 1994, 292, 107. [44] E. Desimoni, B. Brunetti, Glassy Carbon Electrodes Film-Modified with Acidic Functionalities. A Review, Electroanalysis 2012, 24, 1481.

[45] J.-H. Jung, J.-H. Jeon, V. Sridhar, I Oh, Electroactive graphene-Nafion actuators, Carbon 2011, 49, 1279.

[46] N.N. Salama, S.M. Azab, M.A. Mohamed, A.M. Fekry, A novel methionine/palladium nanoparticle modified carbon paste electrode for simultaneous determination of three antiparkinson drugs, RSC Adv. 2015, 5, 14187.

[47] S. Shahrokhian, M. Ghalkhani, Simultaneous voltammetric detection of ascorbic acid and uric acid at a carbon-paste modified electrode incorporating thionine-nafion ion-pair as an electron mediator, Electrochim. Acta 2006, 51, 2599.

[48] A. Walcarius, S. Rozanska, J. Bessière, J. Wang, Screen-printed zeolite-modified carbon electrodes, Analyst 1999, 124, 1185.

[49] L. Tang, Y. Wang, Y. Li, H. Feng, J. Lu, J. Li, Preparation, structure, and electrochemical properties of reduced graphene sheet films, Adv. Funct. Mater. 2009, 19, 2782. 
[50] Y. Cai, Y. Zhang, S. Su, S. Li, Y. Ni, Electrochemical studies oxidation of ciprofloxacin at nano-SnO 2 /PVS modified electrode and its interaction with calf thymus DNA, Front. Biosci. 2007, $12,1946$.

[51] A.J. Bard, L.R. Faulkner, Electrochemical Methods: Fundamentals and Applications, $2^{\text {nd }}$ Ed., Wiley, New York, 2001, p. 482.

[52] T.S. Chen, Y.M. Kuo, J.L. Chen, K.L. Huang, Anodic degradation of ofloxacin on a borondoped diamond electrode, Int. J. Electrochem. Sci. 2013, 8, 7625.

[53] K.S. Essa, M. Elhussein, M., A new approach for the interpretation of magnetic data by a 2D dipping dike: J. Appl. Geophys. 2017, 136, 431.

[54] S.M. Azab, H.K.A. Elhakim, A.M. Fekry, The strategy of nanoparticles and the flavone chrysin to quantify miRNA-let 7a in zepto-molar level: Its application as tumor marker, J. Mol. Struct. 2019, 1196, 647.

[55] S.A. Mehanee, K.S. Essa, 2.5D regularized inversion for the interpretation of residual gravity data by a dipping thin sheet: numerical examples and case studies with an insight on sensitivity and non-uniqueness: Earth Planets Space 2015, 67, 130.

[56] A.M. Fekry, M. Shehata, S.M. Azab, A. Walcarius, Voltammetric Detection of Caffeine in Pharmacological and Beverages Samples Based on Simple Nano- Co (II, III) Oxide Modified Carbon Paste Electrode in Aqueous and Micellar Media, Sens. Actuat. B 2020, 302, 127172.

[57] B. Hemmateenejad, A. Safavi, F. Honarasa, Deriving calibration curves at early times of chronoamperograms using the chemometrically resolved net faradaic current, J. Electroanal. Chem. 2015, 755, 221.

[58] S.M. Azab, A.M. Fekry, The application of a bee glue-modified sensor in daclatasvir dual effect detection, New J. Chem. 2017, 41, 11846. 
[59] G. Manasa, A.K. Bhakta, Z. Mekhalif, R.J. Mascarenhas, Voltammetric Study and Rapid Quantification of Resorcinol in Hair Dye and Biological Samples Using Ultrasensitive Maghemite/MWCNT Modified Carbon Paste Electrode, Electroanalysis 2019, 31, 1363.

[60] N.P. Shetti, S.J. Malode, D.S. Nayak, G.B. Bagihalli, S.S. Kalanur, R.S. Malladi, C.V. Reddy, T.M. Aminabhavi, K.R. Reddy, Fabrication of $\mathrm{ZnO}$ nanoparticles modified sensor for electrochemical oxidation of methdilazine, Appl. Surf. Sci. 2019, 496, 143656. 